УДК 316

$10.17213 / 2075-2067-2021-3-77-83$

\title{
СВАДЕБНОЕ ТОРЖЕСТВО В ПРЕДСТАВЛЕНИЯХ СОВРЕМЕННЫХ РОССИЯН
}

\author{
(C) 2021 г. A. A. Синютин
}

\author{
Общероссийская общественная организация \\ "Федерация свадебных специалистов России", г. Москва, Россия
}

\begin{abstract}
Целью исследования является обоснование того, что в условиях современного информационного общества происходит реинтерпретация свадебного торжества и сопровождающих его ритуалов, которое заключается в переносе акцента в интерпретации брака на его индивидуально-личностный характер. Данное обстоятельство ведет к тому, что свадебное событие начинает восприниматься в качестве феномена только индивидуальной жизни, который детерминируется социально-культурными запросами индивида. При этом ритуальное оформление заключения брака утрачивает сакральный смысл, где ритуал сохраняется как «пустая форма».
\end{abstract}

Методологическую базу исследования представляют научные труды В. H. Топорова, А.К. Байбурина, посвященные сочиально-культурному исследованию свадебных ритуалов, потенциил которых не исчерпан в прочессе изучения и осмысления рассматриваемой проблематики. Исследование базируется также на теории Л. И. Ионина о моностилистической и полистилистической типах культур. В конкретно-прикладном плане исследование базируется на соииологическом опросе, проведенном среди разновозрастных групп респондентов.

Результаты исследования. Проведенное эмпирическое исследование по проблеме выявило, что в современном российском обществе свадебная иеремония рассматривается большей частью респондентов как событие личное, при этом индивидуализированная трактовка события, фиксирующего создание брака, делает необязательным свадебную иеремонию, десакрализируя ее и обесиенивая также весь комплекс свадебных ритуалов, сохраняюшихся в виде «пустых форм» и символов, их обозначающих. Функционально сохраняющиеся свадебные ритуалы служат преимущественно организации индивидуальных праздников и самопрезентации, чему в значительной степени способствует популярность инвент-менеджмента, анонимность городской среды, расширение коммуникации средствами сети Интернет.

Перспективу исследования составляет дальнейший социологическкий анализ свадебных ритуалов в контексте гендерных отличий.

Ключевые слова: ритуал; свадьба; социальное поведение; общество; культура.

\section{WEDDING CELEBRATION IN THE VIEWS OF MODERN RUSSIANS}

\author{
(C) 2021 A. A. Sinyutin \\ All-Russian public organization «Federation of wedding specialists of Russia», \\ Moscow, Russia
}

The purpose of the study is to prove the fact that in the conditions of the modern information society, there is a reinterpretation of the wedding celebration, as well as the appropriate rituals, 
which we observe as shifting the emphasis in the interpretation of marriage to its individual and personal character. This circumstance leads to the fact that the wedding event begins to be perceived as a phenomenon only of individual life, which is determined by the socio-cultural needs of the individual. At the same time, the ritual registration of marriage loses its sacred meaning, where the ritual is preserved as an «empty form».

The methodological basis of the research is represented by the scientific works of V. N. Toporov, A. K. Bayburin, devoted to the socio-cultural study of wedding rituals, the potential of which is not exhausted in the process of studying and understanding the issues under consideration. The research is also based on the theory of L.I. Ionin about monostylistic and polystylistic types of cultures. In a concrete and applied sense, the study is based on a sociological survey conducted among different age groups of respondents.

The results of the study. The conducted empirical research on the problem revealed that in modern Russian society the wedding ceremony is considered by most respondents as a personal event, while the individualized interpretation of the event that records the creation of marriage makes the wedding ceremony optional, desacralizing it and devaluing the entire complex of wedding rituals that are preserved in the form of «empty forms» and symbols that denote them. Functionally preserved wedding rituals serve mainly to organize individual holidays and selfpresentation, which is largely facilitated by the popularity of event management, the anonymity of the urban environment, and the expansion of communication via the Internet.

The perspective of the study is a further sociological analysis of wedding rituals in the context of gender differences.

Key words: ritual; wedding; social behavior; society; culture.

Введение. Заключение брака и ритуалы, сопровождающие данное событие, могут быть обнаружены во всех культурах, поскольку являются фиксацией смены жизненного цикла индивида, его/ее переход из одного статуса в другой. В традиционных обществах свадебное торжество в большей степени представляло, скорее, событие локальной общины, чем индивидуальное событие. Брак заключался по социально-экономическим или политическим причинам (династические или аристократические браки), при этом достаточно часто не принималось во внимание мнение самих молодых (жениха и невесты), главными договаривающимися лицами выступали родители с обеих сторон. Личностная неготовность к вступлению в брак с конкретным партнером обусловливала привлечение в качестве своеобразного гаранта всего сообщества такие социальные институты, как церковь, семья, локальные сообщества. При этом участие представителей этих институтов подтверждало общественное значение свадебного ритуала. Вхождение брачующихся в новую фазу жизни и осознание трудностей этой фазы обусловли- вали оформление свадебной церемонии множеством символических ритуалов и знаковых примет. Известный ученый В.Н. Топоров подчеркивал, что свадебные ритуалы служили актуализации «...самой структуры бытия, придавая ей в целом и в ее отдельных частях необыкновенно подчеркнутую символичность и семиотичность, и служат гарантией безопасности и процветания коллектива» [1, с. 16].

Символическое обрамление вступления в брак создавало, в первую очередь, сакральный смысл - совершение таинства, поэтому переживалось также и эстетически. Сакральный смысл этого таинства был связан с телесным элементом перехода брачующихся в новый социальный статус. А.К. Байбурин по этому поводу писал: «...вступление в брак - это не только оформление семейных отношений, переход в новый статус, но и предписанный культурой способ разрешения противоречия между способностью к продолжению рода и необходимостью получения на это социальной санкции» [2, с. 66]. В традиционных восточнославянских культурах получение данной «социальной санкции» основывалось на стро- 
го соблюдаемых ритуалах, которые включали множество обрядов, начиная от предсвадебных, затем непосредственно свадебных, которые завершались послесвадебными, продолжавшимися зачастую в течение года после заключения брака.

В современных условиях активного использования технологических возможностей XXI века происходит нивелирование ранее существовавших границ между приватной и публичной областями жизни, где формируется преобладание установки на самопрезентацию через визуализацию деталей повседневной жизни, позиционирование потребительских практик, которые непременно включают различные праздники и развлечения, а публикация свадебных ритуалов превращается в излюбленные поведенческие практики пользователей Интернета. Собственное или профессиональное режиссирование свадебной церемонии, как правило, создает минимизирование ритуалов, относящихся к сакральности действия, которое в прежние времена охранялось определенными социальными институтами (церковь, община, социальный круг, государство). Следовательно, можно предположить, что в современном информационном обществе сохраняется «культурная форма» свадебного действа (символико-ритуальное оформление), однако видоизменяется доктрина данного события (социально-смысловое наполнение).

Трансформация свадебных ритуалов в полистилистической культуре. В индивидуальном измерении свадебный ритуал связан с изменением социального статуса личности, что требует также изменения идентичности, именно поэтому свадьбу относят к ритуалам перехода. При наличии доктринальной основы, т.е. смысла культурной формы (в данном случае - морального учения о предназначении семьи, четкого описания ролевых требований к мужу и жене, их обязанностям по отношению к детям, родителям, роду и др.), которая признается, поддерживается и контролируется обществом, поведенческие формы соответствуют культурным предписаниям. Сам ритуал выступает реализацией культурной формы и свидетельствует об устойчивости положенной в ее основу доктрины. Л.И. Ионин так определил это яв- ление: «Эти формы можно назвать свободно парящими: они не связаны в их нынешнем состоянии с социальными интересами и через них с определенными слоями и группами. Теперь, когда отсутствует запрет на публичную презентацию, они предлагают себя каждому, кто обеспокоен поиском идентичности, стремится обрести новый целостный образ мира, в котором можно четко фиксировать собственное место» [3, с. 277].

Свадебный ритуал в век технологической и информационной революции во многом воплощается в функции презентации индивидуальных предпочтений, где возможны разнообразные сценарии, начиная от соблюдения традиционной культурной формы до эпатажных театрализованных решений, главную роль в этом играют Интернет и различные социальные платформы. Используя последние, индивиды превращаются в основных участников свадебных ритуалов, поэтому зачастую свадебное торжество становится не публичным действием, цель которого интериоризация новой социальной роли и соответствующих обязанностей, с ней связанными, а скорее напоминает некую сцену, которая становится самопрезентацией с целью произведения соответствующего впечатления на других. Сущность такой знаковокоммуникативной деятельности индивидов И. Гофман связывал с осознанным или неосознанным «стремлением контролировать поведение других, особенно их ответной реакции на его действия» [4, с. 35].

Анализ результатов социологического опроса. Переход общества в информационный этап своего развития связан со значительным расширением свободы индивида по отношению к обществу. Это проявляется в преодолении «привязки» индивида к определенному социальному слою, определенной территории или месту работы. В этих условиях меняется отношение индивида также и к контролирующей функции общества в отношении смыслов его или ее жизненного цикла. Отношение к свадьбе и ритуалам, ее сопровождающим, выступает показателем этой тенденции. Анализ понимания смыслов свадебных ритуалов находился в фокусе внимания нашего эмпирического исследования. Всего было опрошено 633 респондента, из которых 288 (45,5\%) 
мужчин, 345 (54,5\%) женщин. По возрасту респонденты распределились на следующие группы: 18-21 г. - 21,2\%; 22-30 л. $13,7 \%$; 31-40 л. $-33,6 \%$; 41-50 л. $-22,45$; 51-60 л. - 6,8\%; старше 60 л. - 2,2\%. По типу поселения респонденты распределились на группы: в крупном городе и мегаполисе - 57,3\%; в среднем городе (100-500 тыс. чел.) - 22,2\%; в малом городе (до 100 тыс. чел.) - 10,5\%; в сельских поселениях $10 \%$. Анкета рассылалась через Google Формы. Обработка и анализ полученных данных проведены с использованием статистического пакета обработки IBM SPSS Statistics.

Анализ проведенного опроса показал, что большая часть респондентов (вне зависимости от пола и возрастной группы) считают самыми значимыми событиями собственное рождение (или рождение своих детей), свадьбу, смерть. При этом свадьба по степени важности заняла второе место после рождения детей во всех возрастных группах, что косвенно свидетельствует о сохранении ценности брака и семьи во всех поколениях. Ее социокультурный смысл адекватно считывается основной частью опрошенных, что становится очевидным из представленной ниже таблицы 1.

Следует отметить, что лишь $15,3 \%$ респондентов полагают необходимым проведение свадебной церемонии, более $70 \%$ респондентов в каждой возрастной группе готовы отказаться от проведения свадебной церемонии, не считая ее обязательной. Думается, что необязательное значение свадьбы

объясняется тем, что эта церемония в настоящее время переведена в сферу частной жизни, не сопряженной с каким-либо социальными обязательствами (долгом) человека перед ближайшим сообществом (сельской общиной или традиционной многопоколенной семьей). Индивидуализация в понимании бракосочетания и создании семьи просматривается также и в видении респондентами роли родителей на свадебной церемонии. Большинством респондентов всех возрастных групп $(77,8 \%)$ родители рассматриваются не организаторами свадьбы, а «дорогими гостями».

Вместе с тем основное большинство опрошенных планируют устраивать свою свадьбу (или свадьбу своих детей), хотя в ней около $60 \%$ респондентов усматривают только праздничное содержание. Несмотря на то, что большинство респондентов поддерживают точку зрения, согласно которой праздники - это приобщение к социально значимым ценностям, поддержка традиции и чувство интеграции с сообществом, тем не менее, видение респондентами образа своей свадьбы свидетельствует об отказе большинства из них от народных или советских ритуалов, что видно в приведенной ниже таблице 2.

Представленные результаты свидетельствуют о разделении опрошенного массива респондентов на три группы: тех, кто ориентирован на признание своего личного события со стороны различных социальных групп, участниками которых они являются (в совокупности это 32,1\%); тех, кто ориен-

Таблица 1

Распределение ответов на вопрос «Как Вы считаете, какой основной смысл у события бракосочетания?» (\%)

\begin{tabular}{|l|c|c|c|c|}
\hline \multicolumn{1}{|c|}{ Ответы } & $\begin{array}{c}\text { Все \% } \\
\text { от РКО }\end{array}$ & $18-30$ & $31-50$ & $\begin{array}{c}51 \text { и } \\
\text { старше }\end{array}$ \\
\hline Важный переход человека в другой период жизни & 45 & 54,8 & 37,2 & 56,1 \\
\hline Праздник единения жизни молодоженов & 13 & 10,4 & 14,9 & 10,5 \\
\hline Семейное событие молодоженов и их родительских семей & 14,1 & 10,9 & 16,9 & 8,8 \\
\hline $\begin{array}{l}\text { Праздничное событие молодоженов, их родителей, друзей } \\
\text { и знакомых }\end{array}$ & 13,9 & 10,4 & 16,3 & 12,3 \\
\hline $\begin{array}{l}\text { Важное событие для родителей - уход взрослого ребенка } \\
\text { в самостоятельную жизнь }\end{array}$ & 7,9 & 5,4 & 9,3 & 8,8 \\
\hline Бессмысленный, формальный ритуал & 2,5 & 4,1 & 2 & \\
\hline Другое & 2,8 & 3,2 & 2,5 & 3,5 \\
\hline
\end{tabular}


тирован на узкий семейный круг (20,2\%); тех, кто видит в этом событии только факт своей личной жизни $(31,7)$.

Анализ важности свадебных ритуалов свидетельствует о свертывании свадебного церемониала до самого события: предварительные действия - сватовство, обручение, девичник/мальчишник - утрачивают свое функциональное значение, а если и сохраняются, то, преимущественно в качестве внешней формы. Значительно сокращается применение традиционных ритуалов в процессе самой свадебной церемонии. Респонденты всех возрастных групп отдают предпочтения обмену кольцами $(60 \%)$, благословению родителей $(48 \%)$, свадебной одежде невесты (40\%). Представ- ляется, что перечисленные ритуалы имеют в большей степени знаково-символическое содержание. Однако возникает определенное сомнение, что респонденты рассматривают данные ритуалы в качестве сакральных, поскольку даже в обряде венчания большинство респондентов усматривает не религиозное сакральное содержание, а, скорее, эстетическое действо - «красивый торжественный обряд, который запомнится на всю жизнь», $40 \%$ молодежи считают венчание отжившей традицией. Об этом же свидетельствуют распространенные трактовки смысла ритуальных действий на свадьбах (табл. 3).

Хотя более половины респондентов во всех возрастных группах считают, что ри-

\section{Доминирующие образы желательной свадебной церемонии в коллективных представлениях респондентов (\%)}

Таблица 2

\begin{tabular}{|l|c|c|c|c|}
\hline \multicolumn{1}{|c|}{ Ответы } & $\begin{array}{c}\text { Все } \% \\
\text { от РКО }\end{array}$ & $18-30$ & $31-50$ & $\begin{array}{c}51 \text { и } \\
\text { старше }\end{array}$ \\
\hline $\begin{array}{l}\text { Многочисленная свадьба с народными традициями (выку- } \\
\text { пом невесты, венчанием, дарами, похищением невесты и др.) }\end{array}$ & 13,6 & 15,8 & 11,3 & 19,3 \\
\hline $\begin{array}{l}\text { Многочисленная свадьба, но в современном городском сти- } \\
\text { ле без старых народных ритуалов (свадебный наряд, поезд- } \\
\text { ка по городу, фотосессия, банкет в престижном месте и др.) }\end{array}$ & 25,6 & 27,6 & 27 & 8,8 \\
\hline $\begin{array}{l}\text { Экономный семейный праздник с родителями и близкими } \\
\text { друзьями }\end{array}$ & 20,2 & 22,2 & 18 & 26,3 \\
\hline Молодежная тусовка с различными приколами (конкурсами) & 3 & 2,7 & 3,7 & - \\
\hline Виртуальная свадьба, будем праздновать в соцсетях & 0,3 & 0,9 & - & - \\
\hline Регистрация и сразу отъезд в путешествие & 19,3 & 15,4 & 20,3 & 28,1 \\
\hline $\begin{array}{l}\text { Достаточно, если это будет просто фотосессия, а праздник } \\
\text { мы сделаем на двоих }\end{array}$ & 5,1 & 3,6 & 6,2 & 3,5 \\
\hline $\begin{array}{l}\text { Достаточно просто зарегистрировать брак без всяких об- } \\
\text { рядов }\end{array}$ & 6 & 7,2 & 5,1 & 7 \\
\hline Другое & 7 & 4,5 & 8,5 & 7 \\
\hline
\end{tabular}

Таблица 3

Распределение ответов на вопрос «В чем вы видите смысл ритуалов на свадьбе?»

\begin{tabular}{|l|c|c|c|c|}
\hline \multicolumn{1}{|c|}{ Ответы } & $\begin{array}{c}\text { Все \% } \\
\text { от РКО }\end{array}$ & $18-30$ & $31-50$ & $\begin{array}{c}51 \text { и } \\
\text { старше }\end{array}$ \\
\hline Способ приобщения к культурной традиции & 55,4 & 56,9 & 52,4 & 69 \\
\hline Спектакль - шоу для жениха и невесты & 19,6 & 23,3 & 18,5 & 10,3 \\
\hline Игры, в которых участвуют все & 25 & 19,8 & 29 & 20,7 \\
\hline
\end{tabular}


туалы выступают механизмом приобщения к культурной традиции, конкретизация популярности ритуалов свидетельствует о том, что такое приобщение имеет только внешнюю форму, которую Л. Ионин определил как «пустую форму». Ответы другой половины респондентов по всем группам указывают на развлекательную трактовку свадебных обрядов.

Празднично-развлекательный характер свадебной церемонии проявляется не только в отказе от большинства символических ритуалов и воспроизводства традиционных ролей на свадьбе всех участников, исключая брачующихся, но и в отношении к месту проведения свадьбы. Теперь это место не связано с семейным домом, а ориентировано на прием гостей и комфортность организации праздника. Одним из самых важных ритуалов выступает проведение фотосессии, так как почти 60\% опрошенных считают обязательной организацию фотосессии с выездом профессионального фотографа. Только 20\% относится к этому отрицательно. В совокупности 55\% респондентов ориентированы на фото-фиксирование самого свадебного события, при этом 33,9\% респондентов ориентированы на постановочные кадры в красивых интерьерах или в природных местах. Распределение позиций по вопросу сюжетов для фотографирования на свадьбе также показывает нечувствительность большинства респондентов к собственно свадебным ритуалам. Внимание большей частью обращается на эстетическую сторону снимков, необходимую для самопрезентации. Об этом же свидетельствует готовность респондентов (22,9\%) довериться опыту фотографа при выборе сюжетов для фотографирования.

Заключение. Рассмотрение смыслов, которые вкладывают респонденты всех возрастов в понимание свадебной церемонии, выбора места ее проведения, устойчивости сохранившихся свадебных ритуалов, фиксировании (сохранении во времени) свадебного события - все это свидетельствует об утвердившемся переводе свадьбы в сферу частной жизни людей, придание ей празднично-развлекательного характера. Этот смысл в настоящее время оттесняет и даже вытесняет глубинный культурно-идентификационный смысл свадебной церемонии для индивидуальной жизни как обряда перехода из одной фазы жизни в другую. Вытеснение этого смысла объясняется легкостью заключения/расторжения брака, многократностью заключения брака. Уход сакрального смысла из свадьбы как сложного комплекса ритуалов объясняет отсутствие в настоящее время какого-либо канона свадебной церемонии, что создает широкое поле для индивидуального экспериментирования с формой.

\section{Литература}

1. Топоров В.Н. Первобытное представление о мире (общий взгляд) // Очерки истории естественнонаучных взглядов в древности. - М., 1982.

2. Байбурин A. К. Ритуал в традиционной культуре. Структурно-семантический анализ восточнославянских обрядов. - СПб.: Наука, 1993.

3. Ионин Л.Г. Социология культуры. М.: Изд. Дом ГУ ВШЭ, 2004.

4. Гофман И. Ритуал взаимодействия: очерки поведения лицом к лицу. - М.: Смысл, 2009.

\section{References}

1. Toporov V.N. Pervobytnoe predstavlenie o mire (obshhij vzgljad) [Primeval representation of the world (general view)] // Ocherki istorii estestvennonauchnyh vzgljadov $\mathrm{v}$ drevnosti [Essays on the history of natural science views in ancient times]. - Moscow, 1982.

2. Bajburin A.K. Ritual v tradicionnoj kul'ture. Strukturno-semanticheskij analiz vostochnoslavjanskih obrjadov [Ritual in traditional culture. Structural and semantic analysis of East Slavic rites]. — Saint Petersburg: Nauka, 1993.

3. Ionin L.G. Sociologija kul'tury [Sociology of Culture]. - Moscow: Izd. Dom GU VShJe, 2004.

4. Gofman I. Ritual vzaimodejstvija: ocherki povedenija licom $\mathrm{k}$ licu [The ritual of interaction: essays on face-to-face behavior]. - Moscow: Smysl, 2009. 


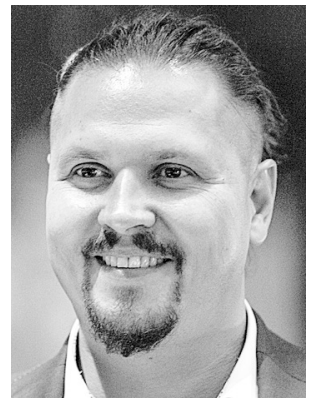

Синютин Александр Александрович - президент Общероссийской общественной организации «Федерация свадебных специалистов России». Выпускник МГИМО (У) МИД РФ. Автор 15 обучающих программ по психологии и бизнесу в сфере культурно-массовых мероприятий.

Sinyutin Alexander Alexandrovich - President of the AllRussian public organization «Federation of wedding specialists of Russia». Graduate of MGIMO (U) MFA of the Russian Federation. Author of 15 training programs on psychology and business in the field of cultural events.

115470, г. Москва, пр. Андропова, 17, корп. 1, кв. 159

17 Andropova av., bld. 1, ap. 159, 115470, Moscow, Russia

E-mail: ssinyutin@mail.ru 